\title{
LA INTELIGENCIA INHUMANA. LA EVOLUCIÓN DE LOS DERECHOS HUMANOS
}

\author{
INHUMAN INTELLIGENCE. \\ THE EVOLUTION OF HUMAN RIGHTS
}

\author{
Raquel Lucía Pérez Brito \\ Universidad de La Laguna
}

Fecha de recepción: 18-9-19

Fecha de aceptación: 22-4-20

Resumen: El debate sobre los avances científicos y sus efectos supera las fronteras nacionales. El poder real se ha desplazado desde los Estados hacia las empresas privadas que controlan globalmente el desarrollo tecnológico, la big data y la sociedad del conocimiento, interfiriendo, así, en la vida de las personas. Por ello es necesario un desarrollo legislativo con vocación universal y con códigos éticos que tengan en cuenta que el desarrollo de la Inteligencia Inhumana está creado por y para la mejora de la humanidad.

El "derecho a la vida" debe situarse en un nivel ontológico superior a cualquier otro derecho universal para garantizar la supervivencia del ser humano y alcanzar una "Era plenamente humana" en contraposición a las corrientes transhumanistas encaminadas a una "Era posthumama".

Abstract: The debate on scientific advances and their effects goes beyond national borders. Real power has shifted from States to private companies that globally control technological development, big data and the knowledge society, thus interfering in people's lives. For this reason, a legislative development with a universal vocation and defined ethical codes that takes into account the development of Inhuman Intelligence is created by and for the betterment of humanity.

The "right to life" must be placed on an ontological level higher than any other universal right to guarantee the survival of the human being and reach a "fully human Era" as opposed to transhumanist currents headed for a "posthumanist Era".

ISSN: 1133-0937

DOI: https://doi.org/10.20318/dyl.2021.6105
DERECHOS Y LIBERTADES

Número 45, Época II, junio 2021, pp. 163-198 
Palabras clave: inteligencia artificial, derechos humanos, posthumanismo, trashumanismo, era plenamente humana.

Keywords:

artificial intelligence, human rights, post-humanism, trashumanism, the fully human era.

\section{INTRODUCCIÓN}

El verdadero germen de lo que se ha denominado Inteligencia Artificial (IA) ${ }^{1}$ comienza en 1952, cuando William Ross Ashby ${ }^{2}$ planteó construir dispositivos que permitieran ser "amplificadores de la inteligencia humana ${ }^{3 "}$, pretendía buscar sinergia entre la inteligencia humana y la información que esperaba que le proporcionaran los programas computacionales con sus algoritmos.

Hoy en día es fácil encontrar asistentes inteligentes en el mercado, que se usan a diario y que cuentan con aplicaciones de todo tipo, desde información inmediata hasta procesadores de textos que ayudan a los humanos en tareas complejas y proporcionan un valor añadido a los sistemas convencionales. De esta manera se consigue una sinergia efectiva entre inteligencia e información.

El término de IA, con todas sus letras, tal y como lo utilizamos hoy en día, se remonta al 31 de agosto 1955, cuando Marvin Minsky, Nathan Rochester, Claude Shannon y John McCarthy vieron la conveniencia de celebrar una conferencia centrada en discutir si todos los aspectos del aprendizaje o cualquier otra característica de la inteligencia humana podían ser replicados de forma precisa hasta el punto de poder construir una máquina capaz de simularlos. Buscaron financiación para este congreso y se celebró en el verano de 1956 en el Dartmounth Collage en Hanover (Estados Unidos).

Este evento, que duró dos meses, se denominó Dartmouth Summer Research Project on Artificial Intelligence 4 . En él, John McCarthy, en su discur-

1 De ahora en adelante se utilizará las siglas IA para expresar el concepto de Inteligencia Artificial.

2 W. ASHBY, Desing for a Brain, John Wiley\& Sons Inc, New York, 1952.

Fue un médico inglés que, desde las especialidades de neurología y psiquiatría, dedicó más de 15 años al estudio científico del cerebro humano. Llegó a establecer estructuras analógicas entre las estructuras del cerebro humano y de las máquinas, especialmente en los mecanismos de feedback. En este libro expuso su concepción de cerebro artificial.

W. ASHBY, An Introduction to Cybernetics, Chapman\& Hall, London, 1956.

4 Conferencia financiada por la Fundación Rockefeller, donde los científicos creyeron que en un plazo de diez años serían capaces de igualar la mente humana. Objetivo que aún no se ha cumplido. 
so, define por primera vez el término Inteligencia Artificial como la ciencia e ingeniería de hacer máquinas inteligentes. El objetivo, en aquel momento les pareció más sencillo, de lo que ha resultado ser con el paso de los años.

Algunos de los factores que intervienen, tanto en el aprendizaje como en la propia inteligencia humana, siguen siendo un misterio para el hombre. Por eso, los robots existentes no son tan autónomos ni con una inteligencia tan completa como la de los seres humanos.

Analicemos, ahora, si es correcto el término popularizado, desde entonces, de Inteligencia Artificial.

\section{CONCEPTODE INTELIGENCIA ARTIFICIAL VERSUS INTELIGENCIA INHUMANA}

Al igual que pasa en muchas áreas de la ciencia y del conocimiento, intentar definir el concepto de IA resulta complejo y no hay consenso en la comunidad de científicos que se dedica a su estudio y desarrollo.

$Y$ es que el propio concepto de inteligencia no cuenta con una definición asumida por todos, ya que no se ha llegado a entender los componentes esenciales que comprenden la inteligencia o la capacidad mental. Las líneas de investigación se centran en cómo se puede medir la inteligencia, cómo se puede trabajar y qué factores pueden explicar las diferencias individuales en el rendimiento.

Ante la dificultad de entender lo que es la inteligencia, Linda Gottfredson ${ }^{5}$ trata de describir la inteligencia desde una perspectiva funcional, sin hacer distinciones entre humana o artificial, de tal manera que considera que la inteligencia es una capacidad mental muy general que, entre otras cosas, implica la capacidad de razonar, planear, resolver problemas, pensar de manera abstracta, comprender ideas complejas, aprender rápidamente y aprender de la experiencia ${ }^{6}$.

5 L. S. GOTTFREDSON es profesora de psicología educacional en la Universidad de Delaware. Licenciada en psicología y doctorada en sociología, ha realizado múltiples estudios sobre la inteligencia, en especial aquella aplicada a los ámbitos de la selección de personal e influencia social.

6 L. S. GOTTFREDSON, “Why g Matters: The Complexity of Everyday Life”, INTELLIGENCE, vol. 1, pp.79-132.

https://www1.udel.edu/educ/gottfredson/reprints/1997whygmatters.pdf

ISSN: 1133-0937

DOI: https://doi.org/10.20318/dyl.2021.6105
DERECHOS Y LIBERTADES

Número 45, Época II, junio 2021, pp. 163-198 
Hay bibliografías enteras que revisan la historia del concepto de inteligencia y sus diferentes escuelas.

La inteligencia no se puede conceptualizar tratando de hacerla depender de un único factor general y tampoco de muchos pequeños factores específicos.

"Actualmente el concepto de inteligencia empieza a ser concebido no ya como algo que se tiene o no se tiene, ni solamente algo que se tiene más o menos, sino como algo que se va haciendo o deshaciendo" ${ }^{7}$.

Si al concepto de inteligencia le añadimos el adjetivo de artificial, las dificultades se agudizan. Como ya hemos visto, la IA tiene su origen en el esfuerzo que hacen los humanos por hacer pensar a las computadoras con el objetivo de imitar la inteligencia humana.

Efectivamente, tal y como ya indicaba Henry Charles Mishkoll, si existiera una definición concisa y universalmente aceptada sería mucho más fácil llegar a un conocimiento preciso de la IA. Aún en el siglo XXI existe un amplio desacuerdo en lo que significa este término ${ }^{8}$.

Hay dos corrientes claramente diferenciadas, por un lado, hay autores que no quieren que una máquina pueda llegar a albergar capacidades mentales similares a las de los Homo Sapiens y, por lo tanto, ponen en acento en las facetas no conseguidas por la IA y que sí caracterizan a la inteligencia humana ${ }^{9}$ intentando evidenciar la brecha existente aún entre ambas. Por el contrario, los entusiastas con el desarrollo tecnológico de la IA y la robótica enfatizan las posibilidades reales que hay de alcanzar el nivel de la mente humana a través de una máquina.

L. S. GOTTFREDSON, "Where and why g matters: Not a mystery”, Human Performance, vol. 15 núm. 1/2, 2002, pp. 25-46. L. S. GOTTFREDSON, jobs and life, in H. NYBORG (ed.), The scientific study of general intelligence: Tribute to Arthur R. Jensen, Elservier, Oxford, 2003, pp.293-342.

7 C. MOLERO MORENO; E. SAIZ VICENTE y C. ESTEBAN MARTINEZ, “Revisión histórica del concepto de inteligencia: Una aproximación a la inteligencia emocional", Revista Latinoamericana de psicología, núm. 1, 1998, pp.11-30.

8 H. C. MISHKOFF, A Fondo: Inteligencia Artificial, Anaya Multimedia, Madrid, 1988, p.11.

Traducido al castellano de la obra Understanding Artificial Intelligence, publicada por Howard W. Sams \& Co. 1985.

9 L. AMADOR HIDALGO, Inteligencia Artificial y Sistemas Expertos, servicios de publicaciones de la Universidad de Córdoba, series monográficas, núm. 244, 1996.

DERECHOS Y LIBERTADES

ISSN: 1133-0937

Número 45, Época II, junio 2021, pp. 163-198

DOI: https://doi.org/10.20318/dyl.2021.6105 
Es lógico entender que el propio término popularizado de IA ha generado recelos éticos y morales cuando se trata de comparar al humano con un robot en cuyo interior se encuentra un algoritmo que le permite ejecutar ciertas actividades que se podrían considerar inteligentes o propias de una mente. Si el objetivo es conseguir que las máquinas puedan llegar a tener mente, se podría haber llamado, desde el principio, a este concepto de otra forma. $\mathrm{Si}$ se hubiera denominado mente o inteligencia sintética, como ya sugirió John Haugeland, muchas suspicacias hubieran desaparecido. Los robots no son más que máquinas sintéticas que el hombre ha sido capaz de crear, esta inteligencia implicaría que está hecha por y para los humanos, pero sin ser una imitación. Tal y como expresa, con claridad, Haugeland, nadie discute que los aviones vuelen y sin embargo no se les denomina aves, ni se les ha llamado aves no animales o aves máquina ${ }^{10}$.

Alguien, y con razón, podría argumentar que la palabra "sintética" está dentro del campo de la química, es decir, un elemento químico que no aparece de forma natural en la Tierra y que sólo puede ser creado artificialmente. Pero quedémonos con la parte del concepto de sintético que interesa. Lo realmente relevante es que el robot, con cierta inteligencia, que, de momento, no ha sido capaz de igualar las capacidades de los Homo sapiens, no se encuentra en la naturaleza. Su existencia se debe, en cualquier caso, a la creación humana y al deseo de progreso y evolución de los hombres.

No obstante, por otro lado, para ciertos autores trashumanistas, que desean que el desarrollo tecnológico permita crear un robot no sólo para que imite las capacidades humanas, sino que el objetivo final es, efectivamente, que llegue a ser capaz de igualar e, incluso, mejorarlas, el concepto de IA no debería ser el apropiado.

Abundando en esta idea, estos autores dan por hecho que, en el fondo, los humanos no son más que computadoras que aún no se han llegado a comprender, por lo tanto, desde el momento en que se desentrañe el funcionamiento del cerebro humano y se pueda replicar en una máquina utilizando los algoritmos pertinentes, en principio para igualar a la inteligencia humana, con toda probabilidad será cuestión de horas que la inteligencia humana se quede muy por debajo de la inteligencia de los robots.

Este tipo de inteligencia debería estar identificado con la superinteligencia, dejando a la inteligencia de los humanos en un nivel inferior o sub-inteli-

10 J. HAUGELANG, Inteligencia artificial, Siglo XXI, $4^{\circ}$ ed., Madrid, 2003. Traducido de Artificial Intelligence, the very idea, $1^{\circ} \mathrm{ed}$, the Massachsetts Institute of Technology, 1985.

ISSN: 1133-0937

DOI: https://doi.org/10.20318/dyl.2021.6105
DERECHOS Y LIBERTADES

Número 45, Época II, junio 2021, pp. 163-198 
gencia. Por lo tanto, también en este caso, el término de Inteligencia Artificial tampoco representa ni pone en valor lo que realmente podría llegar a ser capaz de hacer comparada con la inteligencia humana.

Efectivamente, es un hecho demostrado, a tenor de la evolución del Homo sapiens en los últimos 30.000 años, que la inteligencia de los robots evoluciona y evolucionará más rápido de lo que podría hacerlo por si sola la inteligencia de la raza humana.

Por todos estos motivos, consideramos que es más apropiado el concepto de Inteligencia Inhumana. El adjetivo inhumano nos permite identificar un ente, como su nombre indica, que no es humano, que además está desprovisto de la capacidad de sentir afecto, comprensión y solidaridad hacia los humanos. El adjetivo inhumano define perfectamente lo que es un robot, independientemente de las capacidades extraordinarias que pueda albergar gracias a los algoritmos que los humanos sean capaces de diseñar. Si se da por hecho, como debería ser, que la utilidad que se le da y se le dará a dicha inteligencia inhumana está encaminada, exclusivamente, a proteger y mejorar la raza humana, no tendría, en ningún caso, que equipararse inhumano con el adjetivo de cruel, con el que se suele identificar.

Con el término de Inteligencia Inhumana se consiguen dos objetivos. Por un lado, no compararla con la inteligencia humana, estaríamos ante una forma de inteligencia auténtica al no ser una imitación y, por otro, hay que enfatizar que es una inteligencia creada por y para el hombre, cuya principal función es mejorar la calidad de vida y amplificar la inteligencia humana.

Podríamos definir la Inteligencia Inhumana como la combinación de algoritmos planteados con el propósito de crear máquinas que presenten algunas capacidades similares que podrían ser peores, iguales o mejores a las que puede desempeñar el ser humano con el objetivo de facilitar y mejorar la calidad de vida de la humanidad. La tecnología no puede dejar de ser un instrumento para convertirse en un fin. Este cambio de papeles, que se puede producir con facilidad, comparto con el filósofo alemán Jonas Hans, el papel fundamental que juegan los resultados científicos-tecnológicos ${ }^{11}$ que, en algunos casos, moralizan a la población y en otros ocurre todo lo contrario haciendo referencia a resultados, por ejemplo, relacionados con la biogenética y el mejoramiento humano.

11 J. HANS, El principio de responsabilidad. Ensayo de una ética para la civilización tecnológica, trad. J. Ma Fernández Retenaga, Herber, Barcelona, 1995, pp. 270-272. 


\section{3. ¿EL DESARROLLO TECNOLÓGICO NOS DEBERÍA PREOCUPAR?}

Stephen Hawking, en una entrevista concedida a la BBC en el 2014, aseguró que el desarrollo avanzado de la IA podría significar el fin de la raza humana, ya que la IA despegaría por sí misma y se rediseñaría a un ritmo cada vez mayor.

"Los humanos, que están limitados por la lenta evolución biológica, no podrían competir y serían reemplazados" ${ }^{\prime 2}$.

Es interesante hacer constar que Hawking padecía una enfermedad degenerativa que le condenaba a una vida casi vegetal y la tecnología facilitó que pudiera desplazarse y comunicarse ${ }^{13}$. Incluso fue capaz de escribir la Breve Historia del Tiempo ${ }^{14}$, el mayor bestseller de divulgación científica publicado hasta el momento. Lo normal es presuponer que, precisamente él, elogiaría los avances tecnológicos ya que, gracias a ellos, había tenido una vida digna, teniendo en cuenta sus circunstancias. Sin embargo, sus declaraciones alertaron sobre las consecuencias que podría tener la creación de una IA que pudiera igualar o superar a los humanos.

En octubre del 2016, durante la inauguración del centro de inteligencia artificial de la Universidad de Cambridge, manifestó que creía que no había muchas diferencias entre lo que un cerebro biológico puede lograr en comparación con una computadora. Según él, las grandes inversiones que se están realizando en la tecnología han permitido que la inteligencia artificial esté progresando rápidamente, hasta el punto de que la mente de los humanos podrá ser amplificada y cuando esto ocurra los logros de las próximas décadas serán inimaginables. Es cierto que también pensaba que, quizás, la tecnológica podría deshacer parte del daño causado al mundo natural por la industrialización e, incluso, erradicar la enfermedad y la pobreza.

12 https://www.abc.es/tecnologia/informatica-software/20141202/abci-stephen-hawking-peligros-inteligencia-201412021837.html? ref $=$ https $\% 3$ A $\% 2 F \% 2 F w w w . g o o g l e . c o m \% 2 F$ recuperado en agosto 2019.

13 S. HAWKING utilizó un sistema de comunicación fabricado por Intel con un desarrollo incipiente de IA. Este sistema aprendía del vocabulario utilizado por el científico y de esta forma era capaz de proponer palabras y frases para agilizar su comunicación. La predicción de texto le permitió comunicarse a la velocidad con la que un adulto teclea un móvil.

14 S. HAWKING, A Brief History of Time: From the Big Band to Black Holes, Bantam Books, Reino Unido, 1988. 
Estaba totalmente convencido de que todos los aspectos de nuestras vidas se transformarán.

“En resumen, el éxito en la creación de IA podría ser el evento más importante en la historia de nuestra civilización. Pero también podría ser el último, a menos que sepamos cómo evitar los riesgos. Además de beneficios, la IA también conlleva peligros, como poderosas armas autónomas, o nuevos procesos para que unos pocos puedan oprimir a la mayoría"15.

Un año más tarde ${ }^{16}$, en la revista número 100 de Wired, Stephen Hawking, en sus últimos meses de vida, se manifestó en la misma línea:

"Me temo que la IA puede reemplazar a los humanos por completo. Si la gente diseña virus informáticos, alguien diseñará una IA que mejore y se replique a sí misma. Esta será una nueva forma de vida que supere a los humanos".

Es evidente que de las palabras del científico se desprende una preocupación por las consecuencias que, para los humanos, podría tener el desarrollo vertiginoso que está teniendo la IA y la robótica en general, aceptando que un mundo posthumano podría estar cerca.

Por su parte, el filósofo Nick Bostrom, que dirige el Instituto para el Futuro de la Humanidad en la Universidad de Oxford, considera el desarrollo de la IA como el mayor riesgo existencial para la humanidad, incluso por delante del cambio climático, pero lejos de considerarlo una catástrofe confía en la ciencia y funda la Asociación Mundial Transhumanista, junto con David Pearce, que defendía potenciar las capacidades humanas a través de una hibridación con la tecnología ${ }^{17}$.

15 Discurso de S. HAWKING, en octubre del 2016, durante la inauguración del centro de inteligencia artificial de la Universidad de Cambridge. Se encuentran diferentes noticas en la red que se hacen eco de esta inauguración. Por ejemplo: https://www.elcomercio.com/tendencias/stephenhawking-inauguracion-centro-inteligenciaartificial-universidaddecambridge.html

16 Noviembre del 2017, https://www.wired.com/category/business/artificial-intelligence/

17 N. BOSTROM es un filósofo sueco y director del Future of Humanity Institute de la Universidad de Oxford. El New Yorker lo ha bautizado como "el filósofo del fin del mundo".

Fue uno de los firmantes de la Declaración Transhumanista de 1998 y cofundador de la Asociación Transhumanista Mundial, hoy conocida por Humanity Plus: https://humanityplus.org/

En 2004 cofundó el Instituto para la Ética y las Tecnologías Emergentes, y en 2011 fundó el Programa Oxford Marton: Sobre los Impactos de la Tecnología Futurista.

DERECHOS Y LIBERTADES

ISSN: 1133-0937

Número 45, Época II, junio 2021, pp. 163-198

DOI: https://doi.org/10.20318/dyl.2021.6105 
Por su parte, Elon Musk ${ }^{18}$ teme que el desarrollo de la IA se puede convertir en la mayor amenaza existencial, por lo que recomienda ser muy cuidadoso con el avance de la IA: "La IA no nos matará, pero nos tratará como gatos caseros" ${ }^{19}$. En su opinión, la IA será tan superior a la humana que se podría comparar con las distancias que hay actualmente entre la inteligencia de un humano y un gato.

Bill Gates, al comparar las tecnologías emergentes con la energía nuclear ${ }^{20}$, manifiesta su preocupación por las consecuencias que puede llegar a tener el desarrollo de la IA y pone el acento donde nadie antes lo había hecho. Al asimilar la IA con las armas nucleares da por hecho que, con un uso inadecuado, pueden causar el mismo daño que las denostadas armas nucleares.

La diferencia principal radica en que estas últimas fueron desarrolladas casi en su totalidad por los gobiernos y los ejércitos, pero el desarrollo de la IA recae en los laboratorios universitarios y en las empresas privadas. Según Gates, los gobiernos, despistados, no se están preocupando de la IA como lo hicieron con las armas nucleares.

Raymond Kurzweil ya adelantó que en poco tiempo seríamos capaces de resolver problemas ancestrales y, por supuesto, también aparecerían nuevos problemas en el camino, desconocidos e inimaginables.

La "singularidad ${ }^{21 "}$, término que ha dado título a uno de sus libros ${ }^{22}$, nos hará superar límites que no somos capaces de imaginar en la actualidad.

18 E. MUSK es un empresario sudafricano fundador de SpaceX y Tesla Motors entre otras empresas destacadas.

19 Frases extraídas de una entrevista que le hacen a Elon Musk en Recode Decode.

https://www.vox.com/2018/11/2/18053424/elon-musk-tesla-spacex-boring-company-self-driving-cars-saudi-twitter-kara-swisher-decode-podcast, 2018 (4 julio de 2019).

20 B. GATES, en su discurso de inauguración del Stanford Institute for Human-Centered Artificial Intelligence en la Universidad de Standford. Marzo 2019.

21 "Singularidad", en el mundo matemático, describe una situación en la que ya no se pueden aplicar las reglas normales. Al elegir este título para su libro, haciendo el símil con el término matemático, probablemente quería hacer entender que, cuando la inteligencia inhumana supere la inteligencia humana, las reglas que los humanos han aplicado hasta ese momento ya no valdrán, porque nunca habrían contemplado con anterioridad una inteligencia superior a la de ellos, que avanzara a una velocidad inalcanzable para la raza humana. En ese instante, la vida cambiará para siempre y los conocimientos y las reglas humanas hasta entonces aplicables ya no tendrán ningún tipo de validez.

22 R. KURZWEIL, The Singularity is near. When humans transcend biology, Penguin, New York, 2006, pp. 5-20.

Prologue: The Power of Ideas.

ISSN: 1133-0937

DOI: https://doi.org/10.20318/dyl.2021.6105
DERECHOS Y LIBERTADES

Número 45, Época II, junio 2021, pp. 163-198 
Irving John Good da por hecho que el hombre será capaz de desarrollar una máquina superinteligente y cuando esto ocurra será la última invención del hombre ${ }^{23}$, ya que las máquinas se encargarán de innovar y desarrollar nuevos avances tecnológicos.

Gracias a los desarrollos de la nanotecnología y la biotecnología, los humanos podrán unirse con las máquinas hasta formar una nueva clase híbrida entre humana y robot, los ciborgs ${ }^{24}$ o incluso llegar a crear el Homo Excelsior ${ }^{25}$, autentico superhombre mejorado y modificado genéticamente, siendo así más inteligente y capacitado que el propio ser humano.

Parte del movimiento trashumanista ve con agrado el desarrollo y el uso de las tecnologías emergentes con el objetivo de que el humano pueda ver potenciadas sus capacidades físicas, cognitivas, sensoriales, morales y emocionales ${ }^{26}$, deseando que los avances exponenciales de la tecnología conduzcan al inicio de una nueva Era: "la posthumana”.

Luc Ferrry, trashumanista, ve viable un proyecto de mejora de la humanidad en todos sus aspectos:

“Un amplio proyecto de mejora de la humanidad actual en todos sus aspectos, físico, intelectual, emocional y moral, gracias a los progresos de las ciencias, y en particular de la biotecnología $27 "$.

José Luis Cordeiro ${ }^{28}$ asegura que “entre el año 2029 y el 2045 va a haber computadoras con más transistores que neuronas tiene nuestro cerebro".

23 I. J. GOOD, “Speculations Concerning the First Ultraintelligent Machine”, Advances in Computing, vol. 6 núm. 99, editors: FranzAlt and Morris Rubinoff, New York: Academic, 1965, p. 33.

24 Este término viene de la unión del acrónimo en inglés cyber y organism, Cyborg o ciborg. Fue acuñado por Manfred Clynes y Nathan Kline en 1960 para representar a un humano mejorado por las máquinas. Lo definieron como: «un sistema hombre-máquina en el cual los mecanismos de control de la porción humana son modificados externamente por medicamentos o dispositivos de regulación para que el ser pueda vivir en un entorno diferente al normal».

25 F. H. LLANO ALONSO, Homo Excelsior. Los límites éticos-jurídicos del transhumanismo, Tirant lo Blanch, Valencia 2018, p. 17.

26 Ibidem, pp. 15-22.

27 L. FERRY\&A.MARTORELL, La revolución transhumanista. Cómo la tecnomedicina y la uberización del mundo van a transformar nuestras vidas, trad. A. Martorell, Alianza Editorial, Madrid, 2017, p.35.

28 Profesor fundador de la Singularity University en Silicon Valley. Actualmente está desvinculado de la Universidad. Es vicepresidente de Humanity Plus y miembro de la Academia Mundial de Arte y Ciencia. 
Para él, el concepto de singularidad tecnológica define el momento en el cual la inteligencia artificial alcance a la inteligencia humana. Por lo tanto, será en ese preciso momento cuando "acabará la edad humana y empezará la edad posthumana" y en la que podrá construirse un software que asuma la inteligencia combinada de todos los Homo sapiens ${ }^{29}$. Asume la posibilidad científica de la inmortalidad física y la cura de enfermedades incurables actualmente.

Recordemos que en la historia de la humanidad los niveles de progreso han evolucionado lentamente, sólo a finales del siglo XX se acelelaron. Este patrón, cuya velocidad ya no es lineal sino exponencial, viene motivado por algo tan sencillo de entender como que las sociedades más avanzadas tienen la capacidad de progresar a un ritmo más rápido que las sociedades menos avanzadas, al contar éstas con menos conocimiento y menos tecnología.

Por lo tanto, a medida que una sociedad alcanza un nivel superior de tecnología, el progreso se acelera y así sucesivamente la velocidad de crecimiento podría llegar a ser tan elevada que se podría alcanzar, en el siglo XXI, un momento en el que no seamos capaces de seguir el ritmo del progreso ${ }^{30}$.

Kurzweil cree que en el siglo XXI se alcanzará un progreso mil veces superior al que ha habido en el siglo $X X^{31}$. Es difícil imaginar cómo serán las comunicaciones dentro de 20 años y tampoco se puede estar seguro de hasta dónde evolucionará la informática, la robótica o la Inteligencia Inhumana.

Nick Bostrom, basándose en la Ley de Moore ${ }^{32}$, planteó que en pocos años se producirá, también, un aumento mil veces mayor en el poder computacional $^{33}$. Y en su libro más reciente ${ }^{34}$, convertido en un bestseller, man-

${ }^{29}$ J. L. CORDEIRO \& D. WOOD, La muerte de la muerte: la posibilidad científica de la inmortalidad física y su defensa moral, Deusto, 2018.

30 R. KURZWEIL, The Singularity is near, cit., Chapter one: The Six Epochs.

31 Ibidem, pp. 84-88.

32 La Ley de Moore es el patrón que utilizan los fabricantes de chips para decidir en qué invertir con el objetivo de seguir siendo competitivos. La consecuencia directa de la ley de Moore es que los precios bajan al mismo tiempo que las prestaciones suben. Para entenderlo, un ordenador comprado hoy dentro de un año costará la mitad y estará obsoleto en dos años. Los nuevos ordenadores costarán más baratos y tendrán más contraprestaciones, velocidad, capacidad, etc. Esta ley se aplica a ordenadores personales y teléfonos móviles principalmente.

33 N. BOSTROM, "How long before superintelligence?”, Investigaciones Lingüisticas y Filosóficas, vol. 5, núm.1, 2006, pp. 11-30.

El Original fue publicado en la revista Int. Jour. of Future Studies, vol. 2, 1998. https://nickbostrom.com/superintelligence.html

34 N. BOSTROM, Superinteligencia: caminos, peligros, estrategias, Teell, 2016.

ISSN: 1133-0937

DOI: https://doi.org/10.20318/dyl.2021.6105
DERECHOS Y LIBERTADES

Número 45, Época II, junio 2021, pp. 163-198 
tiene la preocupación por la raza humana ante los avances de lo que hemos denominado la Inteligencia Inhumana.

Sin embargo, aunque es indiscutible que el aumento de la potencia de los ordenadores, la velocidad y la disponibilidad de datos tiene y tendrá un crecimiento exponencial, esto no garantiza que se pueda alcanzar una inteligencia igual a la humana ${ }^{35}$ capaz de poner en peligro la raza humana o de resolver todos los problemas que hasta ahora no se han podido solventar. Dicho con otras palabras, podremos tener la tecnología necesaria, pero si las capacidades intelectuales humanas no permiten entender las complejidades de su propia mente, de nada servirá, para el objetivo planteado hace más de 60 años, tener toda la tecnología y la velocidad necesarias a nuestro alcance.

Los desarrollos tecnológicos en el mundo de la nanotecnología, la biotecnología, la informática y las ciencias cognitivas (NBIC) permiten pensar que la humanidad se puede estar dirigiendo hacia un ecosistema más acorde a las verdaderas capacidades humanas, que permita alcanzar una "Era plenamente humana" en contraposición a la "Era posthumana" que plantean un cierto sector de trashumanistas ${ }^{36}$.

En la misma línea, Kasparov está convencido de que:

"las máquinas que sustituyen las labores físicas nos permiten concentrarnos más en lo que nos hace humanos: nuestras mentes. Las máquinas inteligentes continuarán con ese proceso, asumiendo los aspectos menores de cognición y elevando nuestras vidas mentales hacia la creatividad, la curiosidad, la belleza y la alegría. Esto es lo que verdaderamente nos hace humanos, y no una actividad o habilidad particular como usar un martillo o incluso jugar al ajedrez $z^{37 \prime}$.

35 M. BODEN, Inteligencia Artificial, Turner Noema, trad. de Inmaculada Pérez Parra, AI. Its Nature and Future, Madrid, 2017, pp. 122-123.

Esta autoría considera "estupideces" las interpretaciones que se hacen de la velocidad tecnológica y de sus consecuencias. Considera totalmente absurdo que la inteligencia artificial combinada con la nanotecnología y con la biología sintética pueda acabar con las enfermedades, con las guerras y hasta con la muerte tal y como pronostican algunos autores. Boden considera que conflictos humanos como el de Oriente próximo o el de Irlanda del Norte o Cataluña no los puede resolver ningún algoritmo. Está convencida de que los que creen en la singularidad realmente ignoran las limitaciones actuales de la IA. Palabras extraídas de una entrevista que le hizo el periódico de El Mundo el año pasado en Madrid.

36 R. L. PEREZ BRITO, "La 'evolución acelerada infosociotecnológica' y sus consecuencias jurídico-laborales”, IUS ET SCIENTIA, núm. 5 vol. 2, 2019, p. 101.

37 G. KASPAROV, Deep Thinking: where Machine Intelligence Ends and Human Creativity Begins, PublicAffairs, Perseus Books, New York, 2017, p. 13. 
Esta "Era plenamente humana" permitirá que la humanidad se centre en el bienestar de la raza humana. Los robots realizarán trabajos que no requieran de las habilidades exclusivamente humanas y el Homo sapiens podrá dedicarse a realizar actividades, que no tienen por qué considerarse trabajo, en las que se consideren útiles y les hagan más felices. El progreso debe ir dirigido exclusivamente al bienestar del humano, de ahí la consideración de encontrarnos en un momento histórico donde es más posible lograr una "Era plenamente humana", gracias precisamente a los desarrollos tecnológicos.

Margaret Boden está convencida de que la Inteligencia Inhumana no llegará al nivel que permita pasar a una "Era Posthumana", pero ayudará a la humanidad. Da por hecho que no será posible que una máquina alcance los niveles cognitivos y de inteligencia humana, ya que el conocimiento real que existe actualmente sobre el cerebro humano no lo permite ${ }^{38}$. Los que opinan lo contrario, según su opinión, son personas que están formadas en otro campo de investigación científica muy distinto al de la Inteligencia Inhumana y les falta conocimiento de los progresos reales ${ }^{39}$. Boden añade un nuevo matiz, que nos parece interesante y discutible ${ }^{40}$, los robots no van a superar al humano porque no saben que pueden hacerlo y por lo tanto tampoco pueden quererlo. Es un hecho que los ordenadores no están comprometidos con los proyectos en los que trabajan, no se emocionan y como consecuencia de ello, no tienen la necesidad de asumir el control, ni el poder, porque no sienten ese deseo ni saben lo que significa ${ }^{41}$.

\section{CLASIFICACIÓN DE LA INTELIGENCIA INHUMANA}

Hay que hacer un análisis del desarrollo de la Inteligencia Inhumana para comprender la rapidez con la que se han sucedido los diferentes hitos en los últimos 25 años.

38 M. BODEN, Inteligencia Artificial, Turner Noema, traducción de Inmaculada Pérez Parra, AI. Its Nature and Future, Madrid, 2017, pp. 122-123.

39 Afirmaciones que realiza en una entrevista que le hicieron en España: http://lab.elmundo.es/inteligencia-artificial/margaret-boden.html, 2018 (6 de julio 2019).

Considera que las palabras tanto de Nick Bostrom como de Stephen Hawking sirven para infundir temor a lo desconocido. En el caso de Hawking, valora los grandes méritos del científico en el campo de la física, pero resta credibilidad a sus conocimientos en el campo de la IA.

40 Se analizará más tarde en el apartado 5, pág. Referencia 54.

41 Palabras utilizadas en el discurso que abrió en la sexta edición del encuentro Thinking Party en el Espacio Fundación Telefónica que se celebró en Madrid a finales del 2018 sobre la Inteligencia Artificial. 
En febrero de 1996, se jugó en Pensilvania el primer encuentro de ajedrez entre un ordenador de la empresa IBM conocido con el sobrenombre de Deep Blue contra, nada menos que, el campeón del mundo de ajedrez Kasparov. En esa primera ocasión, el ruso Kasparov salió victorioso al ganar tres partidas, empatar dos y perder una. Sin embargo, el 11 de mayo de 1997, en Nueva York, se produce el acontecimiento más relevante y sobrecogedor, al mismo tiempo, de la historia del ajedrez. Ese día Deep Blue venció a Kasparov.

Se requirió poco más de un año para mejorar la tecnología y vencer al campeón del mundo de ajedrez. Kasparov llegó a dudar, en aquel momento, de que la máquina realmente lo hubiera vencido y creyó que había sido un humano, dando una orden directa e inesperada en una determinada jugada al ordenador, lo que había provocado su derrota. De cualquier manera, el resultado era lo de menos.

Lo realmente relevante fue tener la certeza de que una máquina podía pensar, recalcular y ejecutar correctamente más rápido que un humano. Deep Blue no requirió, como Kasparov, de años de entrenamiento, aprendizaje, tácticas y experiencia para conseguir un resultado similar al campeón mundial de ajedrez. Por lo tanto, se evidenció que la velocidad para analizar datos y tomar decisiones una vez que los algoritmos correctos se han instalado dentro del ordenador ya son inalcanzables para el cerebro humano. Desde entonces hasta ahora la Inteligencia Inhumana no ha hecho más que alcanzar nuevos hitos.

Existe un amplio consenso en la comunidad científica al considerar que podemos clasificar la Inteligencia Inhumana en cuatro tipos concretos de Inteligencia bien diferenciados. La importancia de conocerlos radica en entender en qué momento se encuentra nuestra sociedad y hacia donde se están dirigiendo los avances tecnológicos.

Siguiendo el criterio de Hintze ${ }^{42}$, Deep Blue estaría en el primer escenario, es decir, lo que se ha denominado "Máquinas reactivas" o de "inteligencia estrecha", conocida como ANI ${ }^{43}$, por sus siglas inglesas. Deep Blue lo sabe todo sobre el ajedrez, pero no sabe nada de otras cosas. Podrá identificar

42 HINTZE es profesor en la universidad de Michigan de Biología Integrada y Ciencias de la Computación. Pretende crear un robot que pueda aprender por sí mismo, sin necesidad de que el humano esté constantemente aportándole información y algoritmos. Para lograrlo requiere que el robot sea capaz de seguir el mismo proceso de aprendizaje que una persona. Es evidente que no se nace con la experiencia, formación y educación que tenemos actualmente. Toda se debe a un aprendizaje que pretende descifrar y replicar.

43 Artificial narrow inteligence (ANI). Se entrena para hacer una faena muy concreta. Normalmente se usan redes neuronales, que se ajustan a sí mismas para poder realizar estas 
cada una de sus piezas de ajedrez y hacer valoraciones sobre los mejores movimientos y elegir la mejor de todas las opciones buscando un resultado concreto en tiempo real, pero no sabe cómo resolver un problema matemático o traducir al inglés cualquier frase que se le proponga. De ahí la denominación de inteligencia estrecha.

En el segundo escenario, nos encontramos con los robots de "memoria limitada", estos robots pueden mirar hacia el pasado. Los robots dotados con esta inteligencia sí son capaces de aprender, pasando al nivel de machine learning.

Para comprender en qué consisten esta inteligencia, podemos pensar en los coches autónomos como los TESLA. Estos automóviles miden la velocidad y la dirección de los vehículos que circulan cerca de su alcance. Estas observaciones se mezclan con los algoritmos de las reprogramaciones instaladas, con las señales de tráfico, con las experiencias del automóvil tales como cuándo decide y en qué momento cambiar de carril para evitar una colisión o para adelantar a otro vehículo y todo lo hace en tiempo real.

En tercer lugar, nos encontramos con Inteligencias más avanzada. Algunos la han denominado teoría de la mente, otros calibre 2 o Inteligencia general artificial $\mathrm{AGI}^{44}$, por sus siglas en inglés, también llamada IA fuerte o IA de nivel humano. Este tipo de Inteligencia Inhumana pretende alcanzar la inteligencia humana, es decir, ser capaz de desarrollar un robot que pueda realizar cualquier tarea intelectual que realiza un humano. Como ya se ha comentado, según Margaret Boden, el mayor obstáculo tecnológico para llegar a la AGI es que, a pesar de los avances significativos, aún no se sabe interpretar y replicar el comportamiento del cerebro humano y, por lo tanto, se está muy lejos de crear una inteligencia como la del Homo sapiens, con el mismo nivel del lenguaje, sensibilidad, creatividad, imaginación, consciencia, etc. ${ }^{45}$.

Las AGIs deberían ser capaces de razonar, planear, resolver problemas, pensar de manera abstracta, comprender ideas complejas, aprender rápidamente y aprender de la experiencia ${ }^{46}$ si se pretende cumplir con la definición

tareas de la forma más eficiente. La mayoría de las ANIs ya no tienen rivales humanos en los campos en las que se han programado.

44 Artificial General Inteligence (AGI). La inteligencia general es equiparable a la inteligencia humana. Cuando se llegue a este nivel se habrá creado una inteligencia artificial completa. En este nivel, la inteligencia es capaz de crear y modificar ANIs para adaptarse a su entorno o mejorarse a sí misma.

45 M. BODEN, Inteligencia Artificial, cit. pp. 122-124.

46 Para cumplir con la definición que dio de inteligencia Linda Gottfredson. Véase nota 7.

ISSN: 1133-0937

DOI: https://doi.org/10.20318/dyl.2021.6105
DERECHOS Y LIBERTADES

Número 45, Época II, junio 2021, pp. 163-198 
de inteligencia dada previamente. Y aún no hemos llegado a este nivel de Inteligencia Inhumana.

Si algún día se alcanza, y parece que tampoco podríamos afirmar ni negar esta posibilidad, implicará que tanto las personas, los robots o los objetos podrán tener pensamientos y emociones que, evidentemente, afectarán a su propio comportamiento $\mathrm{y}$, por lo tanto, deberían estar dotados también de obligaciones y derechos que los protejan ${ }^{47}$.

El último escenario de desarrollo de Inteligencia que hemos denominado Inhumana estaría formado por máquinas que tengan "autoconciencia". Nick Bostrom ha denominado a este cuarto nivel "superinteligencia artificial" 48 , ASI por sus siglas en inglés, nosotros consideramos que debería llamarse "superinteligencia inhumana". De esta forma los robots, con esta Inteligencia, contarían con los algoritmos desarrollados por los investigadores de diferentes ramas del saber que ya habrían sido capaces de comprender la conciencia humana y replicarla. Si AGI aún está en proyecto, este cuarto nivel, hoy en día, parece imposible que se pueda alcanzar, pero no es menos cierto que se están haciendo grandes esfuerzos para comprender los mecanismos de la memoria, el aprendizaje en general y la capacidad de basar las decisiones en experiencias pasadas que van dirigidos a entender la inteligencia humana.

Si la Inteligencia Inhumana llegara a alcanzar este nivel sería "mucho más inteligente que los mejores cerebros humanos en prácticamente todos los campos, incluida la creatividad científica, la sabiduría general y las habi-

47 Léase:

- A. CELOTTO, “Derechos de los robots”, Derechos en Acción, vol. 11 núm. 11, 2019, pp. 271-271.

- G. LARIGUET, “Humano, demasiado humano: ¿Podrían tener derechos morales (algunos) robots? Un análisis filosófico a partir de dos cuentos de Isaac Asimov". Principia Iuris, vol. 15 núm. 28, 2017, pp. 116-135.

- J.B. NAVARRO, La tutela judicial de los derechos no humanos. De la tramitación electrónica al proceso con robots autónomos. CEFLegal: revista práctica de derecho. Comentarios y casos prácticos, (208), 2018, pp. 55-92.

48 Artificial Super Inteligence (ASI). Este es el escenario que se produciría si AGI llegara a su máximo desarrollo con capacidad para crear ANIs en su interior. De esta manera se vuelve más capaz y rápida. En este nivel de desarrollo la evolución sería exponencial, llegando así a las ASI. Y desde ese momento la inteligencia tendrá unos valores que no serán entendibles para los humanos. La ASI podría alcanzar más inteligencia que el colectivo de la humanidad en un par de semanas tras su aparición. Llegados a ese punto no habría nada que la humanidad pudiera hacer para detener su progreso. Lo cual puede ser aterrador o, todo lo contrario, una esperanza para poder resolver los problemas que hasta ahora no se han podido resolver por las limitaciones de los humanos, según cómo se vea. 
lidades sociales" ${ }^{49}$. Dicho de otra manera, podríamos estar hablando de una computadora que pudiera ser un poco más inteligente que los humanos al principio y en pocas horas billones de veces más inteligente que cualquier ser humano.

Llegados hasta aquí, es lógico que se puedan plantear varios escenarios, por un lado, el negativo, es decir, creer que es posible que los humanos puedan, perfectamente, desaparecer y por lo tanto desear que se pare todo desarrollo tecnológico por precaución. O el positivo, estar convencidos de que los humanos no desaparecerán, precisamente porque las nuevas tecnologías darán una nueva oportunidad a la raza humana, permitiendo, incluso, llegar a ser inmortales gracias a dichos avances.

\section{PRESENTE Y FUTURO DEL DESARROLLO DE LA INTELIGENCIA INHUMANA}

Repasar los acontecimientos recientes permitirá observar la evolución desde la ANI hasta la Inteligencia de memoria limitada y las consecuencias que en la vida humana están teniendo. De esta manera, podremos valorar si realmente es bueno o no para la raza humana contar con este tipo de robots y en qué campos se deberían potenciar y en cuáles frenar su desarrollo si fuese necesario.

En el 2014 IBM presentó el ordenador Watson, con aprendizaje automático denominado computación cognitiva ${ }^{50}$, que permite automatizar el ciclo de vida de la Inteligencia Inhumana. Ya se utiliza en el mundo sanitario, en despachos de abogados, grandes empresas, en la educación y hasta en el mundo de la restauración con el ChefWatson. Cuenta con clientes en 45 países.

Por su parte, Google adquirió la empresa informática DeepMind ${ }^{51}$, que diseñó el programa informático AlphaGo que consiguió vencer al campeón de Europa y un año más tarde, en el 2016, al campeón del mundo de un mile-

49 N. BOSTROM, Superinteligencia: caminos, peligros, estrategias, Teell, Madrid, 2016, pp. 25-38.

50 La computación cognitiva es un tipo de inteligencia inhumana que utiliza una tecnología que permite a las máquinas desarrollar procesos parecidos a los del pensamiento humano. Con esta tecnología se pretende simular los procesos mentales que un ser humano tiene para adquirir un determinado pensamiento. Para ello la IA requiere de sistemas de autoaprendizaje para ser capaces de resolver problemas sin necesidad de asistencia humana.

51 https://deepmind.com/about

ISSN: 1133-0937

DOI: https://doi.org/10.20318/dyl.2021.6105
DERECHOS Y LIBERTADES

Número 45, Época II, junio 2021, pp. 163-198 
nario juego de origen oriental llamado Go, muy popular en Asia, ya conocido en la época de Confucio.

Para comprender el avance de este hito hay que diferenciarlo del ajedrez. En una partida de ajedrez, lo normal es que en cada turno se puedan realizar 37 movimientos de media, pero en Go, se pueden realizar hasta 250 posibilidades de media. La clave del éxito de este programa informático ha sido la capacidad de aprender por sí mismo de una manera similar a la humana, mejorando en cada movimiento su aprendizaje ${ }^{52}$. En estos momentos el programa es capaz de ganar al campeón del mundo humano de cualquier juego que se programe.

Evidentemente la Inteligencia Inhumana ha evolucionado con respecto a Deep Blue de IBM de 1997 que, como ya se ha mencionado, venció al campeón del mundo de ajedrez. En aquel momento, Deep Blue utilizaba distintas redes para evaluar las posiciones en el tablero y seleccionar movimientos que los humanos habían utilizado en partidas anteriores y que se habían introducido en los algoritmos del Deep Blue. En julio del 2019 el campeón del mundo de ajedrez, el noruego Magnus Carlsen, reconoció que su héroe e inspiración es AlphaZero, nada menos que el motor de inteligencia artificial creado por DeepMind para jugar al ajedrez. AlphaZero en su presentación en sociedad, en diciembre de 2017, ya captó la atención del mundo del ajedrez al arrasar al programa de ajedrez mejor del momento, Stockfish, con el que se preparaba la élite de ajedrecistas.

Magnus Carlsen reconoce que nunca ha jugado como lo está haciendo ahora y que estos cambios se los debe al programa AlphaZero, que le ha permitido mejorar y cambiar su estilo de juego al coger ideas prestadas de las partidas del sistema de inteligencia programada. Es decir, se ha invertido el sistema. Deep Blue, Inteligencia Inhumana en los años 1996-1997, copia el comportamiento humano y sólo la rapidez en el análisis del juego y en la ejecución le permite vencer y superar al humano. Con AlphaZero es el humano quien está copiando las ideas de la máquina, permitiéndole mejorar su juego. Aunque el campeón del mundo no podrá vencer a la máquina, sí se produce un cambio radical en su forma de analizar las jugadas al valorar los nuevos movimientos y estrategias que la máquina ha realizado con éxito. La tecnología, en este caso, ha permitido multiplicar las habilidades humanas.

52 G. KASPAROV, Deep Thinking: Where Machine Intelligence Ends and Human Creativity Beguins, PublicAffairs, Perseus Books, New York, 2017. 
AlphaZero es Inteligencia Inhumana que parece tener intuición. Una máquina que se guía por su instinto y que aprende a jugar por su cuenta. Sólo se introdujo un algoritmo con un input: las reglas del juego. Es decir, en qué consistía ganar y los posibles movimientos de cada pieza sin dar ninguna otra instrucción. No se le explicó la importancia o valor teórico de cada una de las piezas tampoco se le indicó ninguna estrategia para comenzar o al finalizar la partida. La máquina sólo requirió saber las reglas del juego sin ningún otro matiz, ni táctica, ni supervisión, ni advertencias. El resultado está ahí, AlphaZero adquirió un nivel de juego en un solo día al enfrentarse a sí mismo 44 millones de partidas, más de mil por segundo. Algo totalmente inalcanzable para ningún humano.

La característica fundamental que lo diferencia de otros sistemas de aprendizaje profundo es que no requiere de supervisión humana, pudiendo, en solo unas horas, alcanzar un nivel de entendimiento del juego superior al del mejor de los humanos en ese mismo juego. No sólo es superior por su capacidad de manejar millones de cálculos por segundo y analizar todos los patrones de desarrollo estratégico posibles, tal y como lo hizo Deep Blue en 1997, sino que también ha conseguido desarrollar características que se creían exclusivas de las personas, como el talento, la creatividad o la intuición.

Es evidente que el robot no es consciente de tener estas cualidades hasta ahora propias de los humanos. La máquina sólo ha hecho lo que se le ha dicho que haga, que juegue y trate de ganar siguiendo unas normas. De ahí que sorprenda el cómo ha aplicado las normas del juego del ajedrez a su manera, sin seguir comportamientos humanos previos. No se le ha explicado lo que es la creatividad, ni la intuición, ni el talento, por lo tanto, no lo ha aprendido y tampoco pretendido y, sin embargo, a la vista de los humanos, lo ha logrado. Esto contradice la opinión de Margaret Boden cuando afirma que los robots no van a superar a los humanos porque no saben que lo pueden hacer $\mathrm{y}$, por tanto, tampoco lo van a querer ${ }^{53}$. Es evidente que la máquina no necesita querer hacerlo para conseguirlo, simplemente llegan al resultado sin más, como un efecto colateral del objetivo real que se había desarrollado en los algoritmos planteados. El ejemplo más claro lo tenemos en AlphaZero y la creatividad, entre otras habilidades, que ha demostrado tener jugando al ajedrez. Por lo tanto, sí podría ser posible que las máquinas, sin querer tener la intención, puedan superar a los humanos si cuentan con los algoritmos que lo permitan. La Inteligencia Inhumana no requiere tener deseos de su-

53 Véase el último párrafo del apartado 3 de este artículo. Referencia 41.

ISSN: 1133-0937

DOI: https://doi.org/10.20318/dyl.2021.6105
DERECHOS Y LIBERTADES

Número 45, Época II, junio 2021, pp. 163-198 
peración, ni siquiera tener el objetivo de suplantar a la especie humana para poder lograrlo, así, sin más.

Pero volvamos a centrar nuestro análisis en lo que podría hacer AlphaZero si en vez de dedicarse a juegos como el go, el ajedrez o el shogi ${ }^{54}$ se dedicase a analizar historias clínicas y a proponer tratamientos e intervenciones sabiendo que el objetivo es salvar o mejorar la calidad de vida del humano. Los resultados, es este caso, también podrían llegar a ser innovadores, sorprendentes y con casi toda probabilidad, plantearían tratamientos que hasta ahora no se le habría ocurrido a ningún doctor/a, o de habérsele ocurrido, lo hubiera descartado, en la mayoría de los casos, por miedo a que saliera mal y se considerase que su atrevimiento pudiera haber causado un perjuicio al paciente. Si realmente AlphaZero se programase, como se ha hecho con Watson, para el campo de la medicina, se abrirían nuevas vías de investigación inimaginables y con mejores pronósticos para todos.

La calidad de vida de los humanos mejoraría considerablemente al poder apoyarse en la Inteligencia Inhumana y complementarla con la capacidad de cruzar los conocimientos de diferentes áreas de conocimiento, cualidad reservada, aún, para humanos.

El futuro en la medicina es realmente prometedor ${ }^{55}$, en todos los sentidos, si se cuenta con el apoyo de la Inteligencia Inhumana. A modo de ejemplo, ya se utilizan sistemas inteligentes terapéuticos para detectar emociones en niños autistas ${ }^{56}$ que permiten interactuar con ellos. Se fabrican prótesis que se conectan al nervio óptico o al auditivo y corrigen determinados tipos de cegueras y sorderas ${ }^{57}$.

Más cercano en el tiempo, el brote de la COVID-19, que tuvo su origen en diciembre del 2019 en Wuhan, China, declarado pandemia por la Organización Mundial de la Salud el pasado 11 de marzo y que, en pocos meses, se ha extendido rápidamente azotando a todo el planeta, ha permitido que, con el apoyo de la Inteligencia Inhumana, se descubriera el genoma ${ }^{58}$

54 Considerado popularmente como el ajedrez japonés.

55 https://www.agenciasinc.es/Noticias/Inteligencia-artificial-y-realidad-virtual-para-ladeteccion-precoz-del-autismo

56 Designing a Socially Assistive Robot for Long-Term In-Home Use for Children with Autism Spectrum Disorders. https://arxiv.org/pdf/2001.09981.pdf

57 https://retina.elpais.com/retina/2018/11/29/tendencias/1543495153_654402.html

58 R. LU, X. ZHA0, J. LI, P. NIU, B. YANG, H. WU \& Y. BI, “Genomic character sation and epidemiology of 2019 novel coronavirus: implications for virus origins and receptor binding", The Lancet, vol. 395 núm.10224, 2020, pp. 565-574. 
en un tiempo record. La comunidad científica está trabajando colaborativamente $^{59}$, como nunca lo había hecho, compartiendo datos e investigaciones realizadas para lograr una vacuna que pueda frenar los resultados tan desastrosos que está teniendo en la salud mundial ${ }^{60}$. La mayoría de los trabajos científicos se publican en abierto y en pocos meses se han logrado resultados sorprendentes. Sin embargo, este duro golpe hace que se replantee, una vez más, el estilo de vida de los humanos ${ }^{61}$.

Se está a la espera de lograr una vacuna que pueda ser efectiva para este virus letal. Con toda probabilidad se conseguirá mucho más rápido de lo previsible gracias a los desarrollos de la nanotecnología, la biotecnología, la informática y la Inteligencia Inhumana. Tal y como ya se ha planteado con anterioridad, es deseable que el desarrollo tecnológico permita una sociedad que se centre en los humanos, tratando alcanzar una "Era plenamente humana".

Después de esta pandemia provocada por la COVID-19, esta opción parece más cercana. Nada será igual una vez que se pueda dar por superada esta crisis mundial sanitaria. Ni el estilo de vida, ni la forma de trabajar, ni la forma de enseñar ni la de aprender. Estamos convencidos que la necesidad actual provocará un desarrollo intelectual muy superior al de los siglos pasados gracias, en parte, al incremento de la capacidad investigadora, al trabajo colaborativo y al apoyo de la Inteligencia Inhumana, que provocará que la innovación y la creatividad humana se aceleren junto con los desarrollos tecnológicos. Es un momento extraordinario, como suele ocurrir en todas las crisis, para que la sociedad pueda salir reforzada de esta situación, al necesitar obligatoriamente que plantearse otras opciones de convivencia y supervivencia para casos similares que pudieran sobrevenir.

La sociedad podría encaminarse hacia un modo de vida mejor, desconocido aún para la humanidad, donde el centro no será la mejora productiva de los países medida a través de su Producto Interior Bruto, sino la mejora del bienestar y la calidad de vida de los ciudadanos en cada Estado, tal y como ya plantean el Banco Mundial y algunos gobiernos como el francés ${ }^{62}$. Es de-

59 https://horizon-magazine.eu/article/covid-19-how-unprecedented-data-sharing-has-led-faster-ever-outbreak-research.html

60 P. RICHARDSON, I. GRIFFIN, C. TUCKER, D. SMITH, O. OECHSLE, A. PHELAN, \& STEBBLING, J. "Baricitinib as potential treatment for 2019-nCoV acute respiratory disease", The Lancet, vol. 395 núm. 10223, 2020, pp. e30-e31.

61 R.L. PEREZ BRITO, La “evolución acelerada infosociotecnológica”..., cit., p. 104.

62 https://www.bancomundial.org/es/news/press-release/2014/08/19/banco-mundial-propiciointercambio-para-medir-la-felicidad página 4.

ISSN: 1133-0937

DOI: https://doi.org/10.20318/dyl.2021.6105
DERECHOS Y LIBERTADES

Número 45, Época II, junio 2021, pp. 163-198 
cir, estamos más cerca del fin de la "Era contemporánea" y el comienzo de la "Era plenamente humana".

\section{LA INTELIGENCIA INHUMANA Y LA DEFENSA DE LOS DERECHOS HUMANOS}

Como ya se ha podido comprobar, la Inteligencia Inhumana es positiva en muchos aspectos para el desarrollo y el bienestar de los humanos, pero, al mismo tiempo, cuenta con aspectos ambiguos e incluso negativos. Es este mundo tan cambiante, la necesidad de legislar y controlar el desarrollo de los avances tecnológicos para que se respeten, en todo momento, los Derechos Humanos $(\mathrm{DDHH})^{63}$ es un debate de actualidad, en los que algunos quieren poner freno y otros todo lo contrario. De cualquier manera, hay que ser conscientes de que los Estados, hasta ahora, no han sido capaces de legislar a la misma velocidad a la que ha evolucionado la sociedad. Parece lógico pensar que mucho menos lo será ahora,teniendo en cuenta velocidad exponencial de los avances tecnológicos ${ }^{64}$.

Recordemos que los DDHH han sido considerados por algunos autores como el conjunto de facultades que, en cada momento histórico, se concretan y son reconocidos por los ordenamientos jurídicos a nivel nacional e internacional ${ }^{65}$. Para Antonio Pérez Luño, esta definición se sustenta en tres pilares el iusnaturalismo en su fundamento, el historicismo en su forma y el axiologismo en su contenido ${ }^{66}$.

Sin profundizar en los contenidos, porque no es el objeto de este artículo, pero basándonos precisamente en dichos pilares, es por lo que de la misma manera que el carácter historicista ha permitido comprender que, dependiendo del contexto histórico, se ha llegado, a partir del examen de la reali-

- Informe de la Comisión sobre la Medición del Desarrollo Económico y del Progreso Social, p. 14. https://www.palermo.edu/Archivos_content/2015/derecho/pobreza_multidimensional/ bibliografia/Biblio_adic5.pdf

- Sarkozy pide que el PIB mida la felicidad: https://elpais.com/diario/2009/09/15/economia/1252965601_850215.html

63 A partir de este momento los Derechos Humanos se nombrarán por sus siglas DDHH.

64 E. MONTERROSSO CASADO, Inteligencia artificial y riesgos cibernéticos: responsabilidad y aseguramiento, Tirant lo Blanch, Valencia, 2019, p.19.

65 A. E. PÉREZ LUÑO, Derechos humanos, Estado de Derecho y Constitución, Tecnos, $10^{\circ}$ edición, Madrid, 2010, pp. 50 y 567.

66 Ibidem, p. 569. 
dad social y de la lógica del sentido común ${ }^{67}$, a una evolución de los DDHH que se conocen como derechos de primera, segunda y tercera generación. Siguiendo este mismo planteamiento, del análisis de la realidad actual y del desarrollo tecnológico de la Inteligencia Inhumana y de la robótica se puede sostener que es necesario un nuevo análisis de los instrumentos necesarios para defender los DDHH.

Cada revolución industrial ha provocado la necesidad de adecuar los DDHH a las circunstancias ${ }^{68}$. Nos encontramos, históricamente hablando, en lo que se ha denominado la cuarta "evolución acelerada infosociotecnológica" 69 , en la que la mejora de la productividad y el desarrollo económico mundial vendrá de la mano de la nanotecnología, la biotecnología, la informática y las ciencias cognitivas, no del factor del trabajo y del capital, como ha ocurrido desde la Primera Revolución Industrial hasta nuestros días.

Efectivamente, como es conocido, nuestra sociedad ha ido transformando su nivel de desarrollo científico y tecnológico en los últimos siglos desde la aparición de las máquinas de vapor, en la era del carbón, hasta la llegada de los ordenadores en 1960 comenzando así la tercera revolución tecnológica ${ }^{70}$. Pero es a partir del 2012, con los desarrollos tecnológicos de la Inteligencia Inhumana y de la Robótica, cuando se da el paso a la cuarta "evolución acelerada infosociotecnológica" donde, entre otros cambios significativos, los ordenadores pueden aprender por sí mismos machine learning.

El internet de las cosas, la nube, los sistemas ciberfísicos, la robótica y la coordinación digital han marcado un antes y un después de nuestra humanidad. Laurent Alexandre ${ }^{71}$ explica este proceso como el paso de la prehistoria

67 Ibidem, p. 577.

68 Ibidem, p. 605.

69 R.L. PEREZ BRITO, La “evolución acelerada infosociotecnológica”..., cit., p. 85.

Este término pretende reflejar que, en el momento actual, se engloban cambios no solo relacionados con la producción industrial sino también en el tecnológico, en la gestión de la información, en la gestión del conocimiento y todo ello modificará la estructura actual de la sociedad.

- En la misma línea E. MONTERROSSO CASADO \& J.A. BADILLO ARIA, “Inteligencia artificial y riesgos cibernéticos...: Responsabilidad Civil y aseguramiento obligatorio de los robots", cit., p. 26.

70 J. RIFKIN, La tercera Revolución industrial. Cómo el poder lateral está transformando la energía y cambiando el mundo, Paidós, Estado y Sociedad, 2011.

71 L. ALEXANDRE, La guerre des intelligences. Commet l'Intelligence Artificielle va révolutionner l'éducation, JC Lattès, 2017. 
de la Inteligencia Inhumana ${ }^{72}$, donde los programas eran tradicionales, con algoritmos que requerían ser ajustados manualmente por las personas, a la historia de la Inteligencia Inhumana o deep learning, donde los algoritmos programados permiten a las máquinas aprender por sí solas. A la Inteligencia Inhumana ya no se la programa, sino que se la educa, hasta que sea capaz de cruzar datos de campos diversos y en ese momento, todo nuestro mundo, tal y como lo conocemos puede cambiar.

No es de extrañar que, cierto sector del transhumanismo tecnológico, cómodo con el nivel de desarrollo actual y confiado en el potencial que puede llegar a alcanzar, haya puesto en tela de juicio la necesidad de contar con DDHH, considerándolos una postura humanista conservadora caduca y antropocéntrica totalmente innecesaria para el futuro que le espera al ser humano ${ }^{73}$, que quedará integrado a una máquina superinteligente que no necesitará de protección de sus DDHH. Autores como Raymonnd Kurzweil ${ }^{74}$ cree que las máquinas inteligentes permitirán un concepto de humanidad totalmente distinto al actual. Pero para este autor es una buena noticia, al considerar que es la solución para que la humanidad no desaparezca, tal y como parece abocada irremediablemente tras los últimos acontecimientos bien de cambio climático o incluso presentes y futuras pandemias muy agresivas. Por lo tanto, que se produzca una simbiosis entre una máquina y un humano no es considerado como una catástrofe evolutiva tecnológica del Homo sapiens, sino todo lo contrario. Se trata de una esperanza que permite al hombre liberarse de su fragilidad biológica. De ahí que la importancia de los $\mathrm{DDHH}$, para los defensores de este posicionamiento, quede totalmente difuminada.

Con lo expuesto hasta aquí, es evidente que los avances tecnológicos esconden peligros silenciosos que afectan y afectarán, sin lugar a duda, a los humanos. Sin embargo, hay que tener claro que el desarrollo tecnológico puede poner en peligro a la propia especie humana, pero a la vez es fundamental y necesario potenciarlo.

Hay que buscar, por consiguiente, mecanismos de protección individualizada para salvaguardar la dignidad humana en el ciberespacio frente a las

72 Alexandre habla de Inteligencia Artificial, sin embargo, en este artículo, por las explicaciones ya dadas, consideramos más adecuado reconocerla como Inteligencia Inhumana.

73 F. H. LLANO ALONSO, Homo Excelsior. Los límites éticos-jurídicos del Transhumanismo, cit., p.16.

74 R. KURZWEIL, How to Create a Mind. The Secret of Human Thought Revealed, Penguin, New York, 2013. 
nuevas tecnologías y el uso masivo de las TICs. Este nuevo contexto requiere de una legislación acorde a las circunstancias que no se habían dado con anterioridad. Nos encontramos en un escenario que sobrepasa las posibilidades de los Estados para poder garantizar los DDHH, es por ello por lo que se requiriere de la colaboración de otros Estados y de los organismos internacionales para poder hacer efectiva la protección del individuo ante nuevas situaciones con un alto potencial para afectar a los DDHH.

Tengamos en cuenta que los Estados no sólo tienen que proteger a sus ciudadanos de estas posibles interferencias, sino que también tendrán la necesidad de defenderse a sí mismos de esta amenaza global y por ello es necesario acuerdos supranacionales, más propio de la tercera generación de los $\mathrm{DDHH}$, porque la globalización no entiende de fronteras estatales.

$Y$ es que para lograr un verdadero equilibrio de justicia social en este nuevo mundo de la información y el conocimiento en el que vivimos, los DDHH no sólo deben proteger a las personas del desarrollo tecnológico, también deben asegurar que el individuo tenga acceso al desarrollo tecnológico sin limitaciones, es decir con libertad, en igualdad de condiciones y con una actitud solidaria para garantizar los mismos derechos que se han pretendido proteger en la primera, segunda y tercera generación de los $\mathrm{DDHH}$, porque de no lograrlo las desigualdades que se llegarán a producir en nuestra sociedad serán aún mayores a las que existían en el siglo XVIII antes de la Primera Revolución Industrial.

El acceso a los desarrollos tecnológicos con libertad e igualdad es tan necesario como la educación obligatoria y gratuita para intentar alcanzar un equilibrio social.

Este nuevo enfoque, en el que se combina, una vez más, la protección particularizada de cada individuo (más acorde con los derechos de la primera generación) con la necesidad de una colaboración supranacional (propia de la tercera generación de los DDHH) para poder garantizar estos derechos individuales, hace pensar a algunos autores, en la necesidad de una cuarta generación ${ }^{75}$ de los

75 J. B. DONAS, "Hacia la cuarta generación de Derechos Humanos: repensando la condición humana en la sociedad tecnológica", CTS+ I: Revista iberoamericana de Ciencia, Tecnología, Sociedad e innovación, vol. 1 núm. 3, 2003. J. B. DONAS, "La cuarta generación de derechos humanos en las redes digitales". Revista TELOS, 2010, pp. 80-89. E. VALDÉS, "Bioderecho, genética y derechos humanos. Análisis de los alcances jurídicos del bioderecho europeo y su posible aplicación en Estados Unidos como fuente de derechos humanos de cuarta generación", Universitas, Revista de Filosofía, Derecho y Política, núm. 17, 2013, pp. 139163. J. V. VILLALOBOS ANTÚNEZ, J.P. HERNÁNDEZ \& M. PALMAR, “El Estatuto Bioético de los Derechos Humanos de Cuarta Generación”, Frónesis, vol. 19 núm. 3, Venezuela, 2012.

ISSN: 1133-0937

DOI: https://doi.org/10.20318/dyl.2021.6105
DERECHOS Y LIBERTADES

Número 45, Época II, junio 2021, pp. 163-198 
derechos universales para adaptarnos a los nuevos tiempos. Sin embargo, desde nuestro punto de vista, no es conveniente ni necesario plantear una nueva generación de los $\mathrm{DDHH}$, porque, de hacerlo, es más que probable que, de continuar la existencia humana, y esperemos que así sea, se podría llegar a largo plazo, en consecuencia, al infinito en las generaciones sucesivas de los DDHH, posibilidad aceptada por el profesor Antonio Pérez Luño:

"La concepción generacional de los derechos humanos implica, más bien, reconocer que el catálogo de las libertades nunca será una obra cerrada y acabada ${ }^{76 \prime}$

Se debe aclarar que tampoco parece válida la opción de considerar que la tercera generación de los DDHH valdría en la situación actual, como algunos autores dan a entender ${ }^{77}$, para encuadrar las necesidades reales existentes porque para ello sería necesario redefinir el significado que hasta ahora se le ha dado a esta generación de derechos de la solidaridad, que garantizan el acceso universal a formas más avanzadas de ciudadanía y civilidad, de libertad y de calidad de vida ${ }^{78}$, ya que estos derechos que se defienden son colectivos y no individuales. En estos momentos la protección individual en el ciberespacio, unida a la protección para asegurar el uso de la propia tecnología, tiene la necesidad de contar con una defensa ideológica individualista y personalizada.

Para desenredar este nudo hay que centrarse en lo que realmente es importante y analizar cuál es el derecho que ha dado sentido a todos los demás que han pretendido proteger cada una de las diferentes generaciones de los $\mathrm{DDHH}$ ya conocidos y que, en nuestro contexto histórico, es precisamente el que está en entredicho por los propios avances tecnológicos y el futuro que auguran los propios trashumanistas a la raza humana.

Parece evidente que ese derecho es, precisamente, el primero que recoge en el Pacto Internacional de Derechos Civiles y Políticos ${ }^{79}$, la supervivencia de la especie humana, es decir, el derecho a la vida. Porque de no hacer nada,

76 A. E. PÉREZ LUÑO, Derechos humanos, Estado de Derecho y Constitución, cit., p. 606.

77 Ibidem, pp. 578 y 606.

“De este modo, los derechos y libertades de la tercera generación se presentan como una respuesta al fenómeno de la denomina contaminación de las libertades, ...en referencia a la erosión y degradación que aqueja a los derechos fundamentales ante determinados usos de las nuevas tecnologías".

78 J. B. DONAS, "Hacia la cuarta generación de Derechos Humanos: repensando la condición humana en la sociedad tecnológica", cit., p. 3.

79 https://eacnur.org/blog/pacto-internacional-derechos-civiles-politicos/ 
en última instancia, el peligro que se podría correr es, precisamente, la desaparición de la raza humana tal y como la conocemos.

Tratar de conseguir un verdadero equilibrio de justicia social en este nuevo mundo del conocimiento requiere de otros planteamientos distintos sobre los que hasta ahora han pivotado los conceptos de libertad, en el caso de los derechos humanos de primera generación; igualdad, en el de segunda generación y solidaridad en el de tercera generación. Del derecho a la vida no cabe duda de que deben depender todos los demás derechos mencionados. Plantear la complementariedad de los diferentes DDHH a la que hace referencia Antonio Pérez Luño ${ }^{80}$, entre otros autores, no parece lógico. Si te falta la vida, es decir, sin esta conditio sine qua non no se puede dar ningún otro derecho por muy universal que sea ni por muy formalmente protegido que se encuentre dentro de cada ordenamiento jurídico.

El ejemplo que utiliza el profesor Narciso Martínez Morán para reflexionar sobre el derecho a la vida, a propósito de la huelga de hambre de un recluso del GRAPO ${ }^{81}$, resulta aclarador.

El derecho a la huelga de hambre provoca, como es lógico, un conflicto entre el derecho a la vida y el derecho a la libertad y según algunos también entraría en conflicto con el derecho a la dignidad ${ }^{82}$. Si se considera prioritario el derecho a la libertad sobre el derecho a la vida se optaría por negar la alimentación forzosa y, por lo tanto, dejarlos morir. Concediendo, así, el derecho a la muerte, porque esa será la consecuencia lógica de los actos ${ }^{83}$. Lo que plantea, en consecuencia, el profesor Martínez Morán es que, al tomar estas decisiones, no se jerarquiza sobre los diferentes derechos que entran en conflicto. De esta manera, si la decisión es dar preferencia al derecho de libertad lo que se consigue es priorizar sobre un derecho que deja de tener

80 A. E. PÉREZ LUÑO, Derechos humanos, Estado de Derecho y Constitución, cit., p. 606.

81 N. MARTÍNEZ MORÁN, “¿Derecho a la vida o derecho a la muerte? a propósito de la huelga de hambre"c oordinado por: J. AYLLON, J. ESCALONA, M ${ }^{a}$.E. GAYO, Liber amicorum Antonio Fernandez-Galiano, Facultad de derecho, UNED, Madrid, 1995, pp. 564-569.

82 Reflexiones similares están ahora de actualidad con la admisión a trámite en el Congreso de los Diputados en Madrid de la Proposición de Ley Orgánica para regular el derecho a la eutanasia. En este caso entraría en conflicto el derecho a la vida y el derecho a la vida digna y el derecho a la muerte por no poder tener una vida digna. Se considera que se tiene derecho a la vida y no una obligación de vivir de cualquier manera.

83 M. ATIENZA, Tras la justicia, Ariel, Barcelona, 1993, p. 114.

Esta conclusión del profesor Manuel Atienza parece que acepta indirectamente el derecho a la eutanasia que no estaba recogido en nuestro ordenamiento jurídico y menos en los términos en los que se estaban produciendo los acontecimientos en España. 
sentido si no estás vivo. Para qué se quiere tener el derecho a la libertad si estás muerto, para qué necesitas la igualdad si ya no existes. Comparto con el profesor Martínez Morán que ese acto de libertad, de no querer alimentarse, destruye el propio acto de libertad para siempre y se produce un contrasentido el aceptar un derecho que eliminará la posibilidad de poder volverlo a utilizar. Por lo tanto, parece lógico pensar que el derecho a la vida debería estar por encima de los demás derechos universales, sean o no protegidos por los diferentes ordenamientos jurídicos ${ }^{84}$. Se ha utilizado este ejemplo de la huelga de hambre, pero bien valdría cualquier otro ejemplo en el que se cuestione el derecho a la libertad de elegir ser un ciborg o un Homo Excelsior, siendo consciente de que esta decisión privará en el futuro del control de tu propia vida al quedar a merced de una inteligencia superior a la humana que no permitirá, con toda probabilidad, volver a la situación inicial, es decir, a ser un humano.

En definitiva, los DDHH sí que deben estar jerarquizados, poniendo el derecho a la vida en un plano ontológico superior al resto de derechos universales y fundamentales, en su caso. De la misma manera que se le confiere a la Constitución de nuestro país un atributo de supra-legalidad, constituyéndose como ley de rango superior a la del resto de los textos legales ${ }^{85}$, ningún derecho, sea cual fuere, puede estar por encima del derecho superior a la vida ${ }^{86}$.

El derecho a la vida debe ser interpretado como el único derecho humano universal en un plano ontológico superior del que dependan el resto de los derechos. Este planteamiento cobra más sentido, si cabe, en el escenario que se presenta con el del desarrollo tecnológico que permite dudar de la supervivencia de la propia especie humana.

84 Pero en este ejemplo, además, el derecho a la libertad se está utilizando, desde nuestro punto de vista, para realizar un fraude de ley. Se permite, en base a un derecho, un resultado que el ordenamiento prohíbe, ya que en España no estaba permitida la eutanasia y tampoco la pena de muerte para los delincuentes.

85 I. ARA PINILLA, Teoría del derecho, Taller Ediciones JB, Madrid, 2005, p. 278.

86 Para los que consideran que este planteamiento puede ir, también, en contra de la dignidad de las personas, insistiría en que sin vida tampoco se puede hablar de dignidad o indignidad. Muy distinto es que la dignidad no se pueda llegar a alcanzar con los medios tecnológicos y médicos que se cuenten disponibles en la sociedad por encontrarse en una situación aparentemente irreversible en el momento que se desee tener el derecho a la muerte. Los argumentos, en este caso, tendrían en cuenta otras matizaciones que no son objeto de este artículo de investigación. 


\section{LA AUDITORÍA NECESARIA DE LA INTELIGENCIA INHUMANA}

Ante la supremacía que pueden llegar a tener los algoritmos, es necesario una legislación fuerte que impida que se produzcan sesgos y se exija transparencia en la toma de decisiones. Esta vigilancia y corrección no puede quedar al arbitrio de las empresas o de los programadores que crean los propios algoritmos. Cualquier Inteligencia Inhumana que afecte a los derechos individuales o se base en datos personales tiene que estar obligatoriamente auditada externamente y por empresas independientes con algoritmos escalables a la misma velocidad que los auditados. La transparencia es necesaria en la toma de decisiones automatizadas para tener una precisión en la predicción y disminuir la desconfianza existente en la Inteligencia Inhumana. Hay que invertir recursos para desarrollar métodos de control que sean escalables y que, a medida que la Inteligencia Inhumana sea más inteligente, los controles también evolucionen al mismo ritmo. Sólo con transparencia se podrá garantizar que los derechos de los humanos no se vulneren.

Un ejemplo claro del peligro individual que se sufre con el desarrollo tecnológico lo expone Cathy $\mathrm{O}^{\prime} \mathrm{Neil}^{87}$ en una de sus investigaciones sobre la toma de decisiones algorítmicas. Ella insiste en el lado oscuro del big data. Según O'Neil los algoritmos que analizan el big data pueden llevar a decisiones que perjudiquen a los más débiles, incrementando la desigualdad, el racismo y además pone en peligro la democracia. O’Neil considera que los algoritmos son opacos, escalables y posiblemente injustos. Este no es un tema menor, todo lo contrario, la transparencia es necesaria en la toma de decisiones automatizadas, ya que el aprendizaje de la máquina y los algoritmos utilizados se podrían comparar con un cerebro que tiene millones de unidades computacionales y que procesan millones de datos, y estas redes terminan generando predicciones y toma de decisiones, en la mayoría de los casos, imposibles de comprobar o de auditar por el ser humano por la cantidad de datos que cada una de ellas contiene. Los resultados suelen ser opacos para el cerebro humano, ya que es imposible revisar cada uno de esos millones de unidades computacionales compartidas y procesadas y la vida humana, de momento, es limitada.

Si no se es capaz de detectar donde está el error o el sesgo introducido, supuestamente, de forma involuntaria por cualquier humano, difícil será po-

87 C. O'NEIL, “Weapons of Math Destruction: How Big Data Increases Inequality and Threatens Democracy", Journal of Information Privacy and Security, vol. 13 núm. 3, 2017, pp. 157-159.

ISSN: 1133-0937

DOI: https://doi.org/10.20318/dyl.2021.6105
DERECHOS Y LIBERTADES

Número 45, Época II, junio 2021, pp. 163-198 
der corregir las desviaciones producidas y se perpetuarán las desigualdades. De ahí la importancia de que a los algoritmos se les haga una auditoría para comprobar que son correctos y que no incluyen sesgos discriminatorios que atenten contra los derechos de los humanos. Es evidente que a medida que el desarrollo tecnológico aumente también aumentará la complejidad, siendo cada vez más difícil o, incluso, imposible el control de los algoritmos por parte de los humanos. Parece sensato pensar que para encontrar los errores que se pudieran producir es necesario auditar los algoritmos. Y, en el futuro, se hará a través de otros algoritmos independientes.

En estos momentos se están desarrollando programas que permitan a la Inteligencia Inhumana ser explicable, un ejemplo lo tenemos en la Agencia de Proyectos de Investigación Avanzada de Defensa de los Estados Unidos (DARPA). Se pretende minimizar los posibles sesgos que pudieran albergar los algoritmos por la introducción de unas pautas incorrectas por parte de los humanos. El objetivo principal es que se pueda desarrollar Inteligencia Inhumana transparente manteniendo el alto nivel de rendimiento de aprendizaje que implica que exista una precisión en la predicción. Con ello los usuarios humanos estarán más cómodos al comprender el mecanismo utilizado y, por lo tanto, se podrá confiar más en los futuros socios inhumanos que se puedan tener en el futuro.

Con la misma preocupación, la Directora General de la Unesco, Audrey Azoulay $^{88}$, en la conferencia anual inaugural de la UNESCO, planteó que los principios éticos deben regir las normas jurídicas que la regulen para garantizar que la inteligencia artificial esté al servicio de las decisiones colectivas, basadas en valores humanistas.

"Las cuestiones planteadas por la inteligencia artificial no son tecnológicas. Se refiere a nuestra propia humanidad, planteando cuestiones científicas, políticas, filosóficas y éticas".

Hay que aprovechar el estado actual de desarrollo de la tecnología para alinear los algoritmos con objetivos convenientes para los humanos, con fines productivos y dotarlos de valores humanos. Es necesario que las especificaciones técnicas y las muestras de los datos de entrenamiento utilizados,

$88 \quad$ La 39a reunión de la Conferencia General de la UNESCO eligió a Audrey Azoulay como Directora General de la UNESCO. Inició su mandato, de cuatro años de duración, el 15 de noviembre de 2017.

https://es.unesco.org/news/audrey-azoulay-nombrada-directora-general-unesco 
así como las fuentes de datos sean públicas. En este sentido ya se ha dado un primer paso con la Declaración de Toronto del 16 de mayo del $2018^{89}$ así como los trabajos del grupo de alto nivel de los expertos independientes de la Comisión Europea ${ }^{90}$ que pretende generar confianza en la Inteligencia Inhumana y que se llegue a un consenso para consequir que los avances tecnológicos sean seguros y mantengan un comportamiento ético aceptado por todos.

Otro aspecto importante que no se debe pasar por alto y que requiere, también, de vigilancia es el que plantea Éric Sadin ${ }^{91}$ en su libro la "Silicolonización del mundo". Según este autor, desde Silicon Valley y debido a su triunfo industrial sin precedentes en la historia de la humanidad se han producido movimientos geopolíticos. No en vano, empresas que dieron sus primeros pasos desde los garajes de las casas de California se han convertido en el centro de desarrollo del aparato militar y de la informática.

No se trata de Estados con la obligación moral de velar por valores como la dignidad, la libertad, la autonomía de la voluntad, la identidad, la igualdad, la democracia y el bien común, sino de empresas privadas, con intereses, claro está, privados, que se han hecho con el control mundial de la economía y del conocimiento. No es exagerada la comparación que ha utilizado Éric Sadin al decir que desde Silicon Valley se ha colonizado al mundo, y en esta metáfora, los misioneros que se están utilizando son las propias universidades, las industrias tecnológicas, los think tanks, mientras los políticos de los cinco continentes se sienten obnubilados por el desarrollo de Silicon Valley y pretenden replicar la idea en sus territorios bajo la fórmula de "ecosistemas digitales y de incubadoras de empresas start-up".

Éric Sadin no está sólo en esta preocupación, Marcus Weldon ${ }^{92}$ también ha puesto el acento en los movimientos geopolíticos indiscutibles que

89 The Toronto Declaration: Protecting the rights to equality and non-discrimination in machine learning systems

https://www.accessnow.org/the-toronto-declaration-protecting-the-rights-to-equality-and-nondiscrimination-in-machine-learning-systems/

90 https://ec.europa.eu/commission/presscorner/detail/es/IP_19_1893

91 E. SADIN, La silicolonización del mundo. La irresistible expansión del liberalismo digital, Caja Negra Editora, Buenos Aires 2018.

92 M. WELDON, es el presidente del Bell Labs y Director Corporativo de Tecnología NOKIA. Está considerado una de las personalidades más influyentes de la industria de la IA. Palabras sacadas de una entrevista que le hicieron en el Financial Times en abril 2019. También en: https://www.fiercewireless.com/wireless/nokia-s-weldon-needs-10-years-or-more-to-invent-future 
está provocando el desarrollo tecnológico. No se trata solamente de ser conscientes de lo que pueden llegar a hacer o incluso llegar a ser los algoritmos que utilizan los Machine Learning o los avances de las nuevas capacidades de computación tanto a nivel de grandes sistemas como de pequeños sensores. También hay que entender y asimilar que las consecuencias del control de los avances tecnológicos están provocando movimientos geopolíticos indiscutibles. Sin lugar a duda, se ha desplazado el poder hacia los que cuentan con el conocimiento, el desarrollo tecnológico y el manejo de la big data.

Laurent Alexandre ${ }^{93}$ da un paso más y analiza cómo el poder tecnológico se está desplazando desde California hacia la zona de Asia y el Pacífico. Este siglo ya está viviendo una competición por la inteligencia, es decir, las empresas tecnológicas buscan captar a los mejores coeficientes intelectuales humanos. Y esa competición se está produciendo, efectivamente, entre las empresas GAFAM (siglas que corresponden a Google, Amazon, Facebook, Apple y Microsoft ubicadas en Silicon Valley) y su competidora en Asia, BATX (que equivale a las empresas Baidu, Alibaba, Tencent y Xiaomi). El poder tecnológico que comenzó en Estados Unidos y que ahora ya tiene rival en Asia, vendrá, incuestionablemente aparejado, en el corto y medio plazo, a un desplazamiento del poder político y económico.

En estos momentos, la crisis sanitaria mundial provocada por la pandemia causada por la COVID-19 ha permitido, una vez más, visibilizar la capacidad de reacción del Gobierno Chino ante una situación inédita, así como su capacidad industrial para convertirse en el proveedor oficial, en el primer cuatrimestre del 2020, del mundo entero del material clínico necesario para hacer frente al coronavirus.

Para garantizar un uso adecuado de los avances tecnológicos es necesario legislar con carácter universal y ser capaces de auditar los comportamientos de la Inteligencia Inhumana para garantizar la privacidad, el consentimiento ${ }^{94}$ y la supervivencia de la especie humana.

93 L. ALEXANDRE, La guerre des intelligences. Commet l'Intelligence Artificielle va révolutionner l'éducation, JC Lattès, 2017.

94 R. DE ASIS ROIG, "Ethic and Robotics. A first approach", The Age of Human Rights Journal, núm 2, 2014, pp. 1-24, p. 19. 
Es probable que Zygmunt Bauman ${ }^{95}$ tenga razón cuando afirma que:

"Nos encontramos actualmente en un período de interregno: un estado en el que los viejos modos de vida aprendidos y heredados ya no sirven en la actual conditio humana, pero los nuevos modos de afrontar los retos y los nuevos modos de vida no se han inventado todavía".

Ante la situación actual de confinamiento sufrido por la pandemia del COVID-19, la incertidumbre es aún mayor, parece evidente que, una vez superada esta situación, el mundo no volverá a ser como era, lo cual no quiere decir que tenga que ser necesariamente peor al que había antes de esta situación.

\section{CONCLUSIÓN}

La visión que existe sobre el desarrollo de la Inteligencia Inhumana, la robótica y las posibles consecuencias que sobre la humanidad tendrán, no es unánime. Algunos consideran que la supervivencia de la especie humana depende de estos desarrollos tecnológicos y, por tanto, nos encontramos ante el mayor acontecimiento de la historia de nuestra especie. Sin embargo, para otros es la gran amenaza que hay que controlar y, en algunos casos, incluso frenar, ya que temen que pueda acabar con los humanos.

La globalización es fruto del propio desarrollo tecnológico y por tanto no se pueda hablar de un hecho aislado que se pueda contener dentro de unas fronteras estatales, por ello, las posibles ventajas o riesgos que la expansión de la Inteligencia Inhumana y la robótica puedan ocasionar a la humanidad también serán globales. La decisión de hacia dónde se debe dirigir la evolución de la especie humana debe ser coordinada y universal.

Hay que trabajar en un proyecto internacional que permita conocer la situación actual y hacia dónde queremos que se dirija nuestra humanidad y actuar en consecuencia.

Aquí, el desarrollo tecnológico se ha unido al debate del desarrollo evolutivo del hombre. Se ha comprobado, a través del análisis genético de registros fósiles, que el hombre del neolítico era biológicamente igual que los actuales Homo sapiens. El motivo de la extinción de uno y la evolución del

95 Z. BAUMAN, ¿Para qué sirve realmente un sociólogo?, trad. A Capel Tatjer, Paidós, Barcelona, 2014, p.108. 
otro vino motivado por los avances científicos y tecnológicos que se usaron en aquel momento histórico.

No es de extrañar, por tanto, que la evolución natural o darwinista del Homo sapiens parezca detenida e, incluso, en peligro de extinción. La paradoja del destino ha provocado que el desarrollo tecnológico haya puesto en peligro nuestro propio hábitat, provocando un cambio climático que puede acabar con la raza humana, entre otras especies, y, a la vez, que el propio desarrollo tecnológico pueda ser la única solución posible para evitar la desaparición de la especie.

El argumento de los trashumanistas es claro. Si la evolución de la especie a través de la "selección natural" se ha detenido, quizás puede haber una segunda oportunidad con la evolución de la especie a través de una "selección artificial". Los que confían en esta opción pretenden replicar el modelo que observó Darwin de la naturaleza y ejecutarlo en un laboratorio gracias a la ingeniería genética. Los convencidos de que el desarrollo tecnológico salvará a la humanidad, parten de la base de que hay que ampliar las capacidades humanas a nivel individual y colectivo con el uso de los avances en tecnologías cognitivas, biomédicas, biotecnológicas, infotecnológicas y nanotecnológicas.

Nuestro punto de vista mantiene que el desarrollo tecnológico ha sido y será fundamental para mejorar las capacidades de los humanos, pero aún se está muy lejos de comprender la mente humana en su totalidad, aunque cierto es que se han hecho avances significativos. No parece viable el desarrollo inminente de la Inteligencia general artificial (AGI) y, por ende, tampoco se llegará a alcanzar la Superinteligencia artificial (ASI). Sin embargo, es necesario conseguir que los avances tecnológicos sean seguros y mantengan un comportamiento ético aceptado por todos. Los científicos que, desde una rama u otra del saber, investigan los desarrollos de la Inteligencia Inhumana no deberían obsesionarse con igualar o mejorar el cerebro humano.

La raza humana está en desventaja si no se cuenta con la legislación adecuada, con una base ética para que el desarrollo de los sistemas autónomos no se convierta en un peligro para la humanidad, debiendo, por ello, estar programados para defender la vida humana, en todo momento y circunstancia. El desarrollo de inteligencias con capacidad para mejorar la calidad de vida de los humanos debería justificar todos los esfuerzos científicos, pasados, presentes y futuros, siempre y cuando no se ponga en peligro la supervivencia humana. Pero es necesario un acuerdo supranacional para que 
todos los Estados trabajen en la misma dirección. Los acuerdos a los que se lleguen sobre la legislación necesaria para garantizar un uso adecuado y correcto del desarrollo tecnológico, de las Inteligencia Inhumana y la robótica tienen que ser tan globales y universales como lo son las propias tecnologías, que no entienden de fronteras.

Es el momento de aprovechar el estado actual de desarrollo de la tecnología para alinear los algoritmos con objetivos convenientes para los humanos, con fines productivos y dotarlos de valores humanos. Es necesario que las especificaciones técnicas y las muestras de los datos de entrenamiento utilizados, así como las fuentes de datos sean públicas. En este sentido ya se ha dado un primer paso con la Declaración de Toronto del 16 de mayo del 2018 así como los trabajos del grupo de alto nivel de los expertos independientes de la Comisión Europea que pretende generar confianza en la Inteligencia Inhumana.

En este contexto histórico, esta vocación universal tiene gran relevancia ya que el poder real se ha desplazado desde los estados hacia las empresas privadas que controlan los desarrollos tecnológicos y la big data. De lo contrario la colonización que comenzó en Silicon Valley y a la que se ha apuntado también Asia, no habrá hecho más que empezar.

Ante todos estos cambios, presentes y futuros, optamos por una defensa del derecho a la vida como el único derecho universal en un plano ontológico superior del que dependen el resto de los derechos. La protección de los diferentes derechos universales en la actualidad se puede considerar que se encuentran en una situación híbrida entre la primera y la tercera generación de los $\mathrm{DDHH}$, por un lado, se requiere una protección, otra vez, individual, propia de la primera generación, pero esta vez el posible agresor, no son los Estados, sino las empresas tecnológicas privadas con sus algoritmos tanto en el ciberespacio como en los robots que rodearán, cada vez más, a los humanos.

Dicho esto, parece sensato defender que "el derecho a la vida" posee un valor ontológico superior y, por tanto, en caso de conflicto, tiene que estar por encima de cualquier otro derecho y por supuesto de cualquier desarrollo tecnológico.

El derecho a la vida debe situarse en un plano ontológico superior al resto de los derechos universales. Jerarquizando, de esta manera, los derechos humanos y dejando de lado la complementariedad de los DDHH que hasta ahora se ha defendido. El derecho a la vida, como derecho humano univer- 
sal, permite la defensa del individuo con una protección supraestatal frente a esta nueva amenaza, el desarrollo tecnológico, pero también a favor de ese mismo desarrollo tecnológico.

El futuro parece más prometedor que temible si se legisla con carácter universal para poder garantizar el correcto uso a favor de la humanidad del desarrollo tecnológico.

Una frase de Nikola Tesla, a principios del siglo XX, expresa con nitidez lo que deberíamos esperar de los desarrollos tecnológicos:

"La ciencia no es sino una perversión de sí misma, a menos que tenga como objetivo final el mejoramiento de la humanidad".

La nanotecnología, la biotecnología, la informática y las ciencias cognitivas permitirán iniciar una nueva era, la de la plenitud humana; que pondrá el acento en el bienestar humano, diferenciándose de otras corrientes transhumanistas que se encaminan hacia una era posthumana.

Raquel Lucía PÉREz BRITO Universidad de La Laguna Cno. Hornera, s/n - Campus de Guajara, 38200, San Cristóbal De La Laguna Sta Cruz De Tenerife e-mail: rperezbr@ull.edu.es 